\title{
ELS ESPAIS IRRIGATS TRADICIONALS DE NÀQUERA. ESTRATIGRAFIA D'UN PAISATGE HISTÒRIC
}

\author{
THE TRADITIONAL IRRIGATED AREAS OF NAQUERA. \\ THE STRATIGRAPHY OF A HISTORICAL LANDSCAPE
}

\author{
Kilian Cuerda Ros \\ Universitat de València
}

\begin{abstract}
RESUM
En aquest article plantegem l'estudi dels paisatges d'horta tradicional del poble de Nàquera (València), amb l'estudi diacrònic de la seua construcció en la llarga durada, a través de les tècniques de l'arqueologia hidràulica, l'estudi de la documentació històrica disponible, i gestionant la informació amb SIG. Identifiquem els espais agraris d'origen andalusí, així com les ampliacions de les zones irrigades en moments posteriors a la construcció inicial del sistema de reg, i en el període feudal. Així pot traçar-se l'estratigrafia dels paisatges irrigats d'aquest observatori local, que mostra les infraestructures productives tradicionals que formen l'horta com un ens complex, dialèctic, en constant evolució, patrimoni històrico-cultural viu que és document de les societats a les que ha estat vinculat.
\end{abstract}

Paraules clau: Arqueologia hidràulica, arqueologia medieval, SIG, anàlisi del paisatge, patrimoni cultural.

\section{ABSTRACT}

This paper intends to study the traditional irrigated areas of the village of Nàquera (Valencia) with a diachronic study of their construction in the longue duree through the techniques of hydraulic archaeology, the study of the historical documents available and by managing the data with GIS. We identify the crop spaces of Andalusian origin, and also the expansion of the irrigated areas after the initial construction of the irrigation system and during the feudal period. This enables us to outline the stratigraphy of the irrigated landscapes of this local observatory, showing the traditional productive infrastructures which configure the crop space as a complex, dialectic element in permanent evolution, a living historic and cultural heritage which is a document of the societies with which it has been associated.

Keywords: Hydraulic archaeology, medieval archaeology, GIS, landscape analysis, cultural heritage. 
Al terme municipal de Nàquera, situat uns vint quilòmetres al nord de València, a la vessant sud de la serra Calderona, que comprèn vastes zones de secà, els espais irrigats tradicionals es concentren al barranc de Nàquera, quan comença la Calderona, als voltants del nucli urbà actual del poble. Ací mostrem part dels resultats de les recerques en curs per a la tesi doctoral Arqueologia del Paisatge i Patrimoni Cultural a la Serra Calderona. De les hortes andalusines a l'herència de la societat rural tradicional, que desenvolupe sota direcció d'Enric Guinot. Tractem d'identificar els espais de conreu d'origen andalusí, i les ampliacions i evolució dels mateixos durant el període feudal i posterior, en un bon observatori local per a aquesta tasca: Nàquera fou una alqueria andalusina que cauria sota control senyorial amb la conquesta feudal del 1238, i a on romandria la població d'origen andalusí fins l'expulsió dels moriscos de 1609. La metodologia emprada per a la recerca té com a pilar fonamental les tècniques de l'arqueologia hidràulica desenvolupades per Barceló (1989), Kirchner (1995), Glick (2007), Torró (2005) i altres, de les que Guinot i Selma (2008) ofereixen una clara visió.Per a la reconstrucció dels espais d'horta existents s'ha desenvolupat un intens treball de camp de prospecció hidràulica orientada a identificar els elements constitutius de la xarxa d'irrigació i les terrasses que defineixen físicament l'espai de conreu. Aquesta és la via per a la identificació del parcel.lari original que basteix l'horta, més enllà de les parcel.les enteses com a realitat jurídica respecte a la propietat de la terra, de natura variable al llarg del temps. Actualment però, part de les hortes han desaparegut a causa de l'expansió urbana del municipi, per la qual cosa s'ha hagut de recórrer en alguns casos a cartografia i fotografies antigues per a la seua reconstrucció, recolzant-nos en diverses tècniques i eines de teledetecció. Les dades arreplegades i disponibles han sigut tractades amb eines SIG (Sistemes d'Informació Geogràfica), com ara gvSIG o KosmoSAIG, que permeten un treball complex i per capes amb múltiples tipus de cartografia digitalitzada, ortofotografies, dades georreferenciades, així com l'ús d'eines de càlcul i estadística, de dibuix topològic de parcel-laris i sistemes hidràulics i de generació de cartografies. Així mateix, la consulta a la documentació disponible també és fonamental, si bé aquesta és reduïda per al període medieval, com sol ser comú en zones de senyoria i de mudèjars. Disposem com a documentació bàsica per a tractar la qüestió que ens ocupa ací els 
materials de la secció "Aigües" de l'Arxiu Municipal de Nàquera, documentació de l'Arxiu Provincial de València i la documentació notarial de l'Arxiu de Protocols del Patriarca de València.

Els espais de conreu irrigat del barranc de Nàquera prenien tradicionalment l'aigua del barranc a través d'assuts (sent el principal el conegut com Assut dels Moros), tant la que circulava normalment pel llit com la provinent d'alguna font, constituint diverses unitats hidràuliques, però en el darrer terç del segle XIX es va unificar l'abastiment dels sistemes hidràulics mitjançant la construcció d'una mina d'aigua al 1889', de la qual es pot veure hui la boca i les restes de l'assut que abans de la construcció de les canalitzacions modernes conduïa l'aigua, i que encara hui abasteix d'aigua una gran bassa per a la irrigació (obra del primer terç del segle XX). Les hortes que tindríem al davant serien la de la Reana, Vinyes, Arrabal, Rere el Forn (també anomenada de l'Alberch), I'Alquible, el Carme, l'Horta Nova i Faixa.

Al voltant de l'organització subactual del sistema de reg a Nàquera, disposem de la documentació conservada a l'Arxiu Provincial de València. A la secció C.3.1. caixa 2232, es troba un expedient del negociat d'aigües, datat al 12 d'abril de 1863, que té com a objecte l'aprovació de l'acord de la junta general de regants sobre la variació del sistema de tandes de les aigües de reg. En aquest expedient es detalla cóm la junta general de regants, formada per propietaris, decideix establir un nou sistema de repartiment de les aigües, de la següent manera:

\section{Nàquera, 25 de mayo}

El alcalde remite original del acta de la junta general de regantes de la cual resulta que de los concurrentes, 11 opinaron por el sistema riguroso de tandeo, campo por campo; 5 por el tandeo de horas en proporción a la tierra de cada partícipe; 2 más se conformaron con este último parecer a condición de reducir a la mitad los días que ahora existen y 1 opinó por el sistema que hoy regía. El presidente adoptó el acuerdo de la mayoría, o sea el primero, y remite original del acta a este Gobierno para la aprobación.

A l'expedient es detalla el reglament aprovat, a on s'especifica que el reg es farà camp per camp, començant per la Reana, després Arrabal, Alquible

1 Arxiu Municipal de Nàquera, Aigües.

2 Arxiu Provincial de València, Secció: C.3.1. Sèrie: Caixa 223. 
i Rere el Forn, per a després passar a Vinyes, que està a l'altra vora del barranc. Aquesta organització del sistema de regs a Nàquera no és vinculable a models situables a l'Edat Mitjana, i menys encara al període andalusí, i I'hem de situar més aviat al context del desenvolupament del capitalisme i del nou Estat liberal i la seua societat al segle XIX3. De fet, es pot veure cóm un grup de regants, amb tota seguretat propietaris benestants, proposen un sistema de distribució de l'aigua en benefici de qui tinguera major propietat de terres, aprofitant el moment de trencament amb el sistema antic (que per altra banda, no es descriu en cap moment: tots els implicats i interessats el coneixien, així que es dona per suposat). Ara però és la referència més antiga que fins al moment hem localitzat al voltant de l'organització dels regs a Nàquera, i així i tot, al menys l'ordre de reg ens permet veure que la configuració i creació de l'horta de Vinyes possiblement es situe en un moment posterior a les altres (si bé a l'Edat Mitjana, doncs apareix en la documentació), a banda d'estar a l'altra banda del barranc, i que les hortes de Reana, Arrabal, Alquible, Rere el Forn, formen un complex del que I'horta del Carme i l'Horta Nova i Faixa es troben separades, rebent l'aigua d'altre brollador situat baix del poble, i dels sobrants del primer sistema. És aquest document una eina per a la reconstrucció regressiva de l'antic sistema de reg a Nàquera, doncs, de la mateixa manera, si el sistema antic de reg no es regia ni per la quantitat de terra en propietat, ni per l'ordre rigorós de tandeig camp per camp des del principi del sistema hidràulic fins al final, es dedueix que en el sistema anterior, hi havia algunes hortes que tindrien preferència sobre altres en el repartiment de l'aigua, ajudant-nos així a plantejar quins espais s'haurien construït abans i quins després.

\section{L'HORTA de la ReANA}

Aquesta horta hui en dia es troba pràcticament desapareguda, excepte algun element descontextualitzat, degut a la construcció de residències de les classes benestants en la primera meitat del segle XX, i a processos urbanitzadors moderns, de manera que per a la reconstrucció aproximada del seu parcel.lari i xarxa de distribució de l'aigua, s'ha emprat fonamentalment la cartografia cadastral elaborada per l'Institut Geogràfic i Cadastral entre 1928 i 1931 (en concret un plànol de 1929, malgrat que ja mostra algunes transformacions urbanitzadores), així com les imatges del vol americà de 1956, que georreferenciades sobre l'ortofotografia actual i de l'any 2000, permeten aproximar prou acuradament la reconstrucció de l'espai agrari.

3 En altres pobles de la zona, com Serra, Olocau o Marines també es poden veure processos molt semblants en la mateixa època a documents anàlegs de l'Arxiu Provincial de València. 
El topònim Reana, segons l'arabista Carme Barceló, podria procedir de l'àrab Rahanna, que hauria evolucionat cap a Reana a causa d'una dissimilació de les dos vocals centrals que passarien a ser $\mathrm{A}$ i E. Tindria relació amb el camp semàntic de l'aigua en moviment. ${ }^{4}$

Aquest espai de conreu s'estenia a la marge dreta del barranc de Nàquera, des de l'Assut dels Moros, principal assut per a la retenció i elevació de l'aigua del barranc per a les hortes del poble fins la construcció de la mina. Aquest assut, encara en peu i amb reforços moderns de ciment, està construït amb grans còdols i pedres del barranc, units amb morter. Retenia l'aigua que baixava pel barranc per a conduir-la a l'horta de Vinyes, a la vora esquerra, i l'horta de la Reana, a la vora dreta, així com a les hortes de l'Arrabal, l'Alquible i Rere el Forn junt al nucli urbà de Nàquera. Ara bé, l'obra subactual visible hui en dia no hauria de considerar-se necessàriament com medieval, doncs és un element de la xarxa hidràulica sotmès a contínues reparacions i reconstruccions, com es pot veure en la documentació fins època moderna, de fet, les actuals restes corresponen a una reconstrucció de l'assut portada a terme al 1872, si bé l'expedient de l'Arxiu Provincial de València ${ }^{5}$ que detalla el procés de planificació i autorització de les obres destaca que es va construir exactament en el mateix lloc on estaven les restes, en aquell moment prou malmeses, de l'antic assut, de menors dimensions.

La sèquia principal que condueix l'aigua fins les hortes de l'Arrabal, l'Alquible i Rere el Forn, després de fer una corba ampla vorejant una terrassa situada junt a l'assut, traça una línia en gran mesura recta, paral.lela al barranc, configurant per a l'horta de la Reana un espai de tendència generalment fusiforme. A la corba, i a l'inici de l'espai de conreu, trobem una bassa, anomenada la bassa de la Reana, la qual seria la bassa originària que acumularia l'aigua arreplegada a l'Assut dels Moros per a les hortes de Nàquera. Com ens mostra la documentació escrita conservada, tenim seguretat de que aquest espai de conreu està en actiu com a zona amb irrigació vers principis del segle XVII segons la documentació disponible amb conreus també de secà malgrat això, al igual que en alguns documents

4 Gil I Ortega, F.; Navarro I Tomàs, A. (1997): Toponímia rural de Nàquera. Tòpica Edetana, Institut d'Estudis Comarcals del Camp del Túria, Buñol. p. 97.

5 Arxiu Provincial de València, Secció E.3.1, Sèrie: Caixa 329

6 Carta Pobla de Nàquera, 1609, Arxiu del Marqués de Boïl i Visita Pastoral de 1619, Arxiu Curial Eclesiàstic de València, en LiuCH, E. (2002): El señorío y la baronía de Náquera, Ajuntament de Nàquera, p. 337-392. 
del segle $\mathrm{XV}^{7}$ als quals també es pot identificar, $\mathrm{i}$ que veurem amb més detall més endavant. ${ }^{8}$ La irrigació en l'horta de la Reana s'organitzava des de vàries sèquies perpendiculars a la sèquia mare, que entrarien en l'espai de conreu seguint en alguns casos les corbes del microrelleu traçades per les parcel.les i generant algunes estructures arborescents, si bé també baixen rectes vers el barranc. A més a més, en algunes de les parcel.les hi havia sènies per a reforçar el reg, al menys que sapiguem, tres. Una junt a la bassa de la Reana, altra en la zona central i la darrera en una de les parcel.les situades vora barranc. Aquestes perforaven el terra a través d'un pou per tal d'arribar a l'aigua subsuperficial, en una zona de concentració de la humitat com és la situada a la vora del barranc. D'aquesta manera, pel fet de que la sèquia principal porte directament l'aigua fins les hortes de l'Arrabal, l'Alquible, Rere el Forn lque com veurem, podem atribuir-los clarament orígens andalusins, concretament com a part irrigada constitutiva del disseny original del sistema), i de que la irrigació interna d'aquest espai s'organitzara com un afegitó a una sèquia mare pensada per a portar l'aigua a altra zona d'horta i no a aquesta en particular, per a una part, i $a m b$ sènies per altra (cosa que fa veure la insuficiència de l'aigua que rebia la Reana, malgrat estar junt l'assut, o que possiblement algunes parcel.les inclús no tingueren dret a aigua de la sèquia), podríem considerar aquesta zona irrigada com una ampliació de l'espai originari de conreu irrigat. No oblidem tampoc el cóm esdevenia amb els canvis del segle XIX que es passara a regar primer per la Reana, com a novetat, cosa que evidencia que prèviament, al sistema antic, aquesta horta no tenia la preferència en l'ús de l'aigua.

L'horta de la Reana ocupava una extensió aproximada d'uns $29.120 \mathrm{~m}^{2}$, és a dir, 2'9 hectàrees. És una mesura homologable en trets generals a les dels espais irrigats andalusins identificats en Balears 9 o altres indrets, si bé en tots aquests casos de zones de muntanya hem de valorar que sovint, l'espai disponible és el que és, i que la morfologia del terreny és un condicionant força important. A l'Arxiu Curial Eclesiàstic de València es conserva

7 Ferrer Navarro, R. (2002): "Documenta Naquera". Las Edades de Náquera. Reconstruir la memoria. Ayuntamiento de Náquera, pp. 118-169.

8 Les transcripcions de documents històrics que ací oferim són les realitzades per Ramón Ferrer i Emili Lluch.

9 Retamero, F. (2006): "Lo que el tamaño importa. Cuándo y por qué se modificaron los antiguos sistemas hidráulicos andalusíes". Arqueología Espacial, 26. pp. 293-310. 
un document generat a la visita pastoral de 1619 a on es fa inventari de les terres que posseïa l'església, i que resulta d'interès rellevant per a aquest estudi per la menció que es fa a mesures, partides i parcel.les. Ací apareix referència a l'horta de Reana:

Item: un pedacito de tierra huerta en la partida de la Reana que será un almud de tierra que en tiempos de los cristianos nuevos confrontaba con tierra de Joan Receptor por parte de arriba, con tierra de Miguel Amodón, con tierra de Pablo Maymón y con el cequiol, y ahora confronta con tierra de Joan Arnal, con tierra de Julián Novella, con tierra de Francisco Rubio y con el cequiol; poséelo al presente la iglesia. ${ }^{10}$

En la reconstrucció que ací oferim del parcel.lari de la Reana hem tractat d'ubicar el més fidelment possible les principals estructures de parcel. lació de l'horta i de constitució física del seu espai, definides per terrasses, sèquies principals o camins (valorant que l'ús de cadastres antics forneix de dades abundants, però reflecteix l'estructura de la propietat d'un moment concret, no necessàriament la parcel.lació antiga), de manera que potser referències tan concretes com l'almud que es cita, no podrien ubicar-se amb total exactitud. L'almud és una unitat de mesura que correspon a $0^{\prime} 125$ fanecades, això és, 103'88 metres quadrats. Així, s'han reconstruït les parcel.les físiques constituents de l'horta, i es pot veure clarament cóm a nivell morfològic, hi ha una marcada tendència en general a l'adaptació al microrelleu i corbes de nivell, característica habitual dels espais irrigats andalusins, que donaria lloc a parcel.les irregulars, excepte a la zona sud de l'horta, on tenen les parcel.les una contrastada ortogonalitat respecte a la resta. Aquestes parcel.les, en general, mostren unes mesures properes a les de les tafulles d'Elx i Múrcia'1 ${ }^{11}$, unitat mètrica andalusina, més que a les mesures forals com la fanecada. Així, apareixen parcel.les de $1061 \mathrm{~m}^{2}, 1080 \mathrm{~m}^{2}$, $1102 \mathrm{~m}^{2}, 1055 \mathrm{~m}^{2}$ ó $1159 \mathrm{~m}^{2}$. Respecte a això, disposem d'altre document de gran interès, datat al 1490 i situat a l'Arxiu dels Protocols Notarials de València, relacionat amb la venda que Amet Fat i la seua dona, Oria, moros de Nàquera, fan al seu senyor, Bernat Roiç de Corella, de diversos bens, com cases, animals, $i$, en el cas que ens interessa, terres:

10 Visita Pastoral de 1619, Arxiu Curial Eclesiàstic de València, en LiuCH, E. (2002): El señorío y la baronía de Náquera, pp. 387-392. 
Item, unam tafulam parum plus vel minus, sitam et positam in orta dicti loci de Naquera prope sementerium dictorum sarracenorum dicti loci, confrontatam cum terra heredum Amet Moar et cum terra Nuzen, uxor Maymoni Fat. ${ }^{12}$

S'han trobat restes de l'antiga necròpoli islàmica en la zona, situada al voltants del carrer Lepanto. Es coneix tant per troballes realitzades ocasionalment des de fa molt de temps, com per una excavació arqueològica desenvolupada amb motiu d'unes obres d'instal.lació de canonades a l'esmentat carrer, ${ }^{13}$ situat en la Reana, per la qual cosa aquesta horta on s'esmenta com a unitat mètrica la tafulla andalusina, seria l'horta que ara estem tractant.

Al mateix document es fa referència a conreus de secà a la mateixa zona:

Item, unum olivare situm et positum in termino dicti loci prope dictum sementerium prout confrontatur cum olivare Machomat Jafer et cum garroferale alami. ${ }^{14}$

Ara però, caldria considerar també la previsió de creixement del sistema hidràulic, i els possibles usos agraris complementaris, per a la comprensió de l'espai de l'horta de la Reana. Molt possiblement en la constitució originària del sistema irrigat a la colonització andalusina es valorara aquesta qüestió, i donat l'anàlisi parcel.lari que hem portat a terme, podríem situar l'ampliació de l'espai irrigat com a dinàmica generada des de la pròpia societat andalusina de Nàquera, sense poder especificar si relacionada amb el creixement demogràfic de la pròpia comunitat local o per a fer front a noves necessitats econòmiques imposades, com les sorgides arran dels canvis esdevinguts després de la conquesta feudal, és a dir, la necessitat de respondre a la fiscalitat senyorial. Per altra banda, el topònim, que com hem vist abans pot fer referència al camp semàntic de l'aigua en moviment, podria estar suggerint-nos el caràcter de zona de pas de la Reana per a l'aigua cap a les altres hortes.

11 La tafulla correspondria en Elx a $953 \mathrm{~m}^{2}$ i en Múrcia a 1118 m²

12 Ferrer Navarro, R. (2002): "Documenta Naquera", pp. 158-159.

13 Notícia publicada en El País edició Comunitat Valenciana, amb data de 24 de febrer de 2014.

14 Ferrer Navarro, R. (2002): "Documenta Naquera". pp 158-159. 


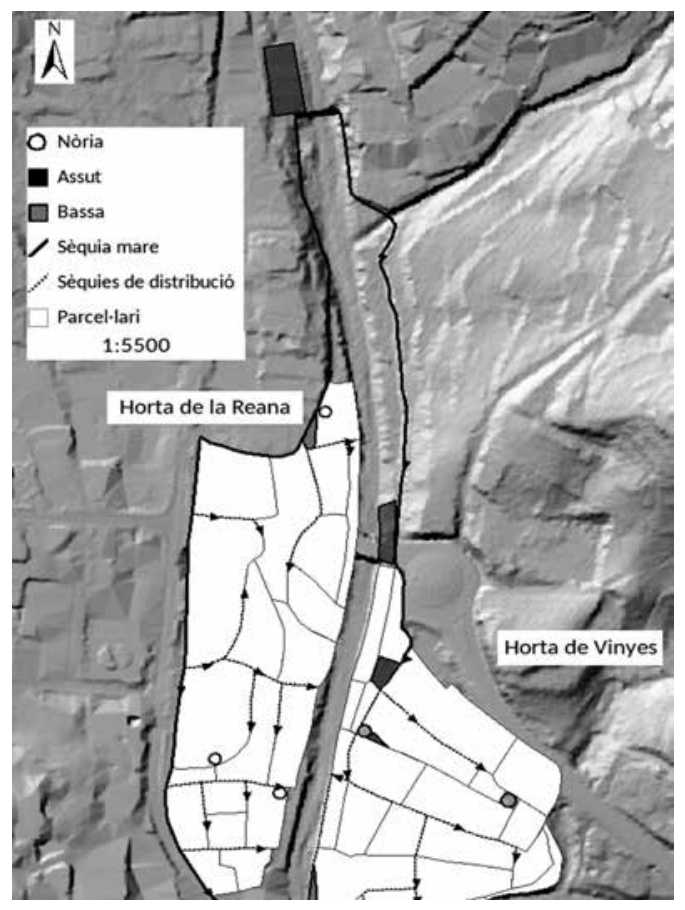

\section{Les hortes de l'Arrabal, Alquible, Rere el Forn}

Després de travessar tota la partida de la Reana per la seua vora, i just abans de trobar-se amb el nucli urbà antic de Nàquera, la séquia es bifurca per a portar l'aigua a les hortes de l'Arrabal i l'Alquible a un costat del poble, a sud-sudoest, i l'horta de Rere el Forn per l'altre, a nord-nordest. L'antic nucli habitat de Nàquera, és a dir, l'alqueria andalusina, es situaria en un promontori sobre una gran corba del barranc, circumdat per aquestes hortes.

L'horta de l'Arrabal i l'Alquible formarien un únic conjunt sobre el terreny, que s'estenia sobre una sort de llengua de terra envoltada per un meandre del barranc, i malauradament està desaparegut hui en dia. El topònim Alquible és clarament d'origen àrab: faria referència al mur de la mesquita orientat vers la Meca. Per a la seva reconstrucció, hem emprat tant la cartografia cadastral antiga com les ortofotografies de l'any 2000, moment en que encara existia aquest espai. L'aigua arribava des de la divisió abans esmentada, traçant una corba que vorejava el nucli habitat, possiblement seguint la corba de nivell que marcava el peu del tossal on es va situar el primer assentament, i arribant a la zona d'horta, a on es dividia en dos ramals que s'obrien a un costat i a l'altre de forma arborescent per tal d'irrigar 
els dos espais, espais constituïts per un conjunt de parcel.les generalment irregulars que s'adaptaven al microrelleu, al igual que la xarxa hidràulica que les abastia. Aquests serien trets característics dels sistemes d'irrigació andalusins.

L'espai irrigat que formen aquestes hortes és de $3^{\prime} 2 \mathrm{ha}$, i també trobem ací, a la documentació disponible, referències a la mesura de les parcel.les en tafulles:

Item, aliam tafulam, sitam et positam in orta dicti loci in partita vulgariter dicta de la Alquibla, confrontatam cum terra Ellell Sufayti et cum terra Çahat Mennag. ${ }^{15}$

A més a més, es dona el cas de que la mitjana de les parcelles, si veiem les estadístiques generades al SIG per a aquesta horta, és de $1186 \mathrm{~m}^{2}$, una mesura molt propera a la de la tafulla de Múrcia.

També al document sobre les possessions de l'esglèsia registrades en la visita pastoral de 1619 apareixen mencions a aquesta zona de conreu i a les unitats de mesura emprades.

Item. A la partida del Alquible, un pedazo de tierra de medio almud que afronta con tierra de Joan Ramón, hijo de Jerónimo, y con tierra de la iglesia y tierra de Joan Barchet; tiene una morera, tiénela arrendada el señor con las de abajo.

Item. Otro pedazo de tierra de almud y medio a la partida del Alquible, que afronta con tierra de Joan Barchet y tierra de la iglesia; tiene garroferas alrededor, tiénela arrendada el señor esta y la de arriba por tres libras dieciséis sueldos cada año.

Item. Un pedazo de tierra de un almud a la misma partida del Alquible que afronta con tierra de la iglesia y tierra de Joan Barchet; tiénela arrendada el señor con lo de arriba.

Item. Otro pedazo de tierra de tres celemines que afronta con tierra de la iglesia por dos partes y con tierra de Joan Ramón Sastre; tiénela arrendada el señor con lo de arriba; tiene alrededor garroferas y una morera.

Item. Un pedazo de tierra a la misma partida que afronta con tierra de Joan Celimet y tierra de Joan Arapel, que tiene la viuda de Mege; tiene una morera; tiénela arrendada el señor con lo de arriba. 
Item. Un pedazo de tierra de una tahúlla a la misma partida que afronta con tierra de Joan Ramón, hijo de Jerónimo Sastre y tierra de los hijos de la viuda de Duquet; está arrendada con las demás que tiene el señor.

Item. Otro pedazo de tierra junto al de arriba, acequia en medio, de celemín y medio, que afronta con tierra de Joan Ramón y tierra de Luis Santo, hijo de Santo, tiénelo el señor con lo demás.

(...)

Primo: en la partida del Alquible, en la huerta, un pedazo de tierra que será medio almud de tierra, que en tiempo de los cristianos nuevos confrontaba de una parte con tierra de Joan Xitiví y de otra con tierra de Santos y de otra con Bernat Pullina y de otra con tierra de Joan Sofayt, cristianos nuevos, y ahora confronta con tierra de Joan Tortajada, con tierra de Miguel Civera, con tierra del señor de Náquera y con tierra de Domingo Ramos y al presente posee dicha tierra Joan Tortajada y la tiene establecida.

Item, otro pedazo de tierra en la partida del Alquible que será medio almud, que en tiempo de los cristianos nuevos confrontaba con Joan Ramón y con tierra de Barchet y con tierra de la iglesia, y tiene una morera y ahora confronta con tierra de Miguel Sanchis, con tierra de Miguel Cervera por dos partes y con tierra de la iglesia, y al presente posee dicha tierra Miguel Cervera.

Item: otro pedazo de tierra en la misma partida del Alquible que será un almud de tierra, que en tiempo de los cristianos nuevos confrontaba con tierra de la iglesia, con tierra de Joan Barchet por dos partes y con el barranco y ahora confronta con tierras de la iglesia, con barranco y con tierra de Miguel Cervera y con garroferas del señor; esta tierra al presente no la posee la iglesia y en el año pasado la sembró el dicho Antonio Vallés.

Item: otro pedacito de tierra en la misma partida que en tiempo de los cristianos nuevos confrontaba con tierra de Joan Barchet y tierra de la iglesia, con garroferas del señor y con tierras de Pablo Maymón y ahora confronta con tierra de Miguel Cervera, con tierra de Joan Tortajada, con garroferas del señor y con tierra de la iglesia; poseélo al presente Miguel Cervera y lo tiene establecido.

Item: otro pedacito de tierra en la misma partida que será almud y medio de tierra que en tiempo de los cristianos nuevos confrontaba con tierras de la iglesia, con tierra de Joan Celim, con tierra de Joan Ubecar y con Jerónimo Canós, cristianos nuevos, y ahora confronta con tierra de Joan Tortajada, con tierras de la iglesia y 
con tierra de Joan Arnal, acequia en medio, posee al presente dicha tierra Joan Tortajada y la tiene establecida.

Item: un pedazo de tierra en un bancal que en tiempo de los cristianos nuevos eran dos bancalitos de tierra en la misma partida que en tiempo de los cristianos nuevos confrontaba con tierra de Joan Celimet, con tierra de Joan Arapel, con tierra de Ballet y con tierra de Jerónimo Solás, cristianos nuevos, y ahora confronta con tierras de Joan Arnal, de Jaime Moreno, con tierras de Joan de Fos, acequia en medio y con tierra del señor a la parte de abajo; tiene una morera y será de una barchilla de sembradura; poseélo al presente Joaquín Monrós, notario, y lo tiene establecido.

Item: en la misma partida del alquible, debajo de la almácera, dos bancalitos de tierra contiguos que tienen nueve pies de garroferas veras y tres pies de garroferas bordes y una morera, que será de un almud de tierra, que en tiempo de los cristianos nuevos confrontaba con tierra de Joan Corayvan, con tierra de Pablo Maymón, con tierra de Solás y con camino a la orilal junto al monte y ahora con tierra de Joan Arnal, con tierra de Francisco Tortajada, con tierra de Vicente Épila mayor y con monte y senda en medio y al presente lo posee la misma iglesia. ${ }^{16}$

Tornen a aparèixer també ací les tafulles, i hi ha com es pot veure un ús molt habitual dels almuds com a unitat de mesura.

Els dos espais, l'Arrabal i l'Alquible, que són un continuum a la vora del barranc, suposen un conjunt coherent, constrü̈t segons uns mateixos criteris de parcel.lació i de bastiment de la xarxa hidràulica. Podem plantejar que la seua construcció va ser contemporània, per part de dos grups de regants del mateix assentament, l'alqueria de Nàquera, i així, relacionats amb la constitució d'aquest assentament andalusí, al igual que l'horta de Rere el Forn o l'Alberch.

L'horta de Rere el Forn, irrigada per l'altre braç de sèquia que sorgeix de la divisió de la sèquia que ve de l'Assut dels Moros, es troba a l'altre costat del poble, formant un espai en forma de mitja lluna a la vora del barranc, sobre una corba de meandre. La sèquia mare, que dona la línia de rigidesa d'aquesta horta, circula formant un ample arc, vorejant la corba de nivell de la vora del poble. A partir d'aquesta sèquia, es basteix sobre

16 Visita Pastoral de 1619, Arxiu Curial Eclesiàstic de València, en LıuCH, E. (2002): El señorío y la baronía de Náquera, pp. 387-392. 
el terreny d'horta una xarxa de sèquies que, segons un traçat que podríem dir arborescent o pintiforme, irriga les parcel.les. L'espai és reduït, i s'adapta la generalitat dels blocs parcel.laris al relleu, ocupant una zona de 1'5 hectàrees, mesura d'horta també coherent amb les altres identificades com andalusines, tant ací com a altres indrets. Ací es dona una troballa prou significativa, que és el fet de que una de les parcel.les identificades, amb límits físics clars, i a la zona central de l'horta (per tant amb menors possibilitats de modificacions dels marges o mesures), té una mesura exacta de 1.189 $\mathrm{m}^{2}$, la mateixa que la mitjana trobada a les hortes de Arrabal i Alquible. Estaríem també davant de la presència de mesures en tafulles, davant de elements propis de la societat rural andalusina per a la construcció dels espais agraris i sistemes irrigats. Aquesta horta es constituiria també com una de les originàries vinculades amb l'assentament dels grups humans andalusins a Nàquera, contemporània a l'Arrabal i l'Alquible.

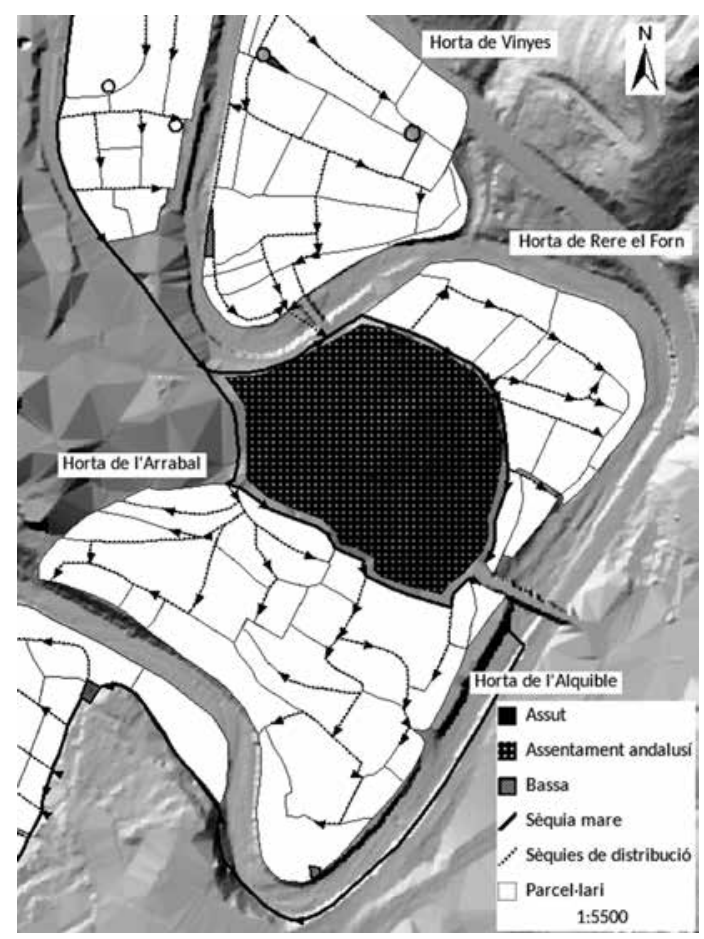

\section{L'Horta de Vinyes}

A l'altre costat del barranc, front la Reana i al nord de la població de Nàquera, es trobava l'horta de Vinyes, hui en dia desapareguda per l'expansió urbanística. La reconstrucció d'aquest espai irrigat ha sigut portada 
a terme mitjançant la cartografia cadastral de 1928-31, les fotografies aèries de l'any 2000 i fotografies realitzades per un veí del municipi, Emili (...) que les ha facilitat per ajudar a aquest estudi.

Aquest espai s'estenia per una zona ampla front al meandre del barranc, i rebia l'aigua d'una sèquia que partia de l'Assut dels Moros, per la marge esquerra del barranc. Aquesta sèquia arribava a una bassa de forma allargada situada a la vora del barranc, just abans de l'horta, i també vessava les seues aigües en altra bassa de forma poligonal situada un poc després, a dins de l'horta, a la part nord de la mateixa. Ací, grans terrasses organitzaven l'espai, en parcel.les de tendència quadrangular, i les sèquies que regaven les parcel.les seguien el traçat general d'aquestes, des de les basses, fent girs d'angle recte, senyal d'una preeminència, pel que fa a criteris de construcció de l'espai irrigat, del que és el repartiment i els blocs parcel.laris sobre la qüestió de la irrigació del conjunt: es planifiquen abans els lots de terra que la sèquia, que s'adapta a aquests. També hi havia un llavador públic a la vora del barranc, amb forma de triangle isòsceles, alimentant per una de les sèquies, i les aigües sobrants d'aquesta horta eren conduïdes per les seues sèquies fins a un aqüeducte que permetia el crevament del barranc, i la incorporació dels recursos hídrics al sistema hidràulic de l'horta de Rere el Forn. També cal esmentar que hi havia dos sènies, una a prop del barranc, amb una bassa annexa de forma triangular, com les citades per Glick ${ }^{17}$, i altra a prop de l'extrem est de l'horta, de la que hem conservat la seva imatge en una de les fotografies d'Emili.

Aquest espai d'horta l'hem de considerar com una ampliació del sistema originari. Es troba a l'altre costat del barranc, irrigat des d'una altra sèquia diferent a la principal, $i$ en el moment de refer el torn de reg al segle XIX, queda igualment situat per darrere de les altres hortes regades des de l'Assut dels Moros en preferència. També, al igual que hem vist en la Reana, trobem sènies, inclús junt a la sèquia, mostra de que o no totes les parcel.les tenien dret a l'aigua, o no arribava suficient. També hi ha dos basses, cosa que es podria deure a una voluntat d'emmagatzemar el màxim d'aigua possible quan hi haguera ocasió per a fer front a un sistema de reg al que l'horta de Vinyes no tenia prioritat en l'ús dels recursos hídrics. Aquestes basses no tenen però per què ser contemporànies. De la mateixa manera, es prenen mesures també per a que els possibles sobrants d'aigua que circulen per ací tornen al sistema de l'altre costat del barranc, mitjançant l'aqüe-

17 Guck, T. (2007): Paisajes de conquista. Cambio cultural y geográfico en la España medieval. Publicacions de la Universitat de València, pp 122-123. 
ducte. Un indici de la mancança de recursos hídrics suficients o de prioritat en l'ús dels mateixos, podria ser la dada que ens dona la documentació, a on a les noves capitulacions que foren signades entre l'alqueria i la senyoria al 1416 es posa al mateix nivell aquesta partida i el secà, declarant-la exempta de pagar l'alcaydia com les altres hortes:

(...) e en lo sequa e en la vinya vella no paguen alguna cosa per lo dit dret de alcaydia. ${ }^{18}$

A la documentació del segle XV conservada, l'esmentat document de venda d'Amet Fat i sa dona Oria al senyor, trobem també referència a l'horta de Vinyes i el sistema métric en ús per a la mesura de les parcel.les:

Item, aliam tafulam terre sitam et positam in termino predicto, in partita de les Vinyes, confrontatam cum terra del duch et cum terra de la mesquita. ${ }^{19}$

Al igual que als altres casos exposats abans, trobem també aci l'ús de les unitats de mesura andalusines conegudes com tafulles. L'espai total d'aquesta horta és de 2'5 hectàrees, i la mitjana parcellària aportada per les estadístiques del SIG és de $857 \mathrm{~m}^{2}$, trobant ací parcel.les amb mesures de per exemple $950 \mathrm{~m}^{2}, 985 \mathrm{~m}^{2}, 1136 \mathrm{~m}^{2}, 1406 \mathrm{~m}^{2}, 1449 \mathrm{~m}^{2}$ i semblants, així com sumes de parcel.les coherents territorial i estructuralment que sumen $1100 \mathrm{~m}^{2}$ ó $1047 \mathrm{~m}^{2}$. Tot això ens situa dins d'un cànon relacionat amb les esmentades mesures andalusines de parcel.lació.

Per això és probable que siga un espai construït després de l'extensió del reg a la Reana. El mateix nom de l'horta, Vinyes (o Vinyes Velles), és indicatiu de la producció que en el passat es donava en la mateixa, vitivinícola, per la qual cosa podríem pensar en una expansió de l'espai irrigat durant el període feudal per a fer front a les exigències de la senyoria, amb productes fàcilment emmagatzemables i fiscalitzables. Ara bé, la presència d'unitats de mesura andalusines en aquest espai seria també mostra de la capacitat de presa de decisions o de control i gestió, al menys en part, en la iniciativa de construir aquest espai de conreu, per part de l'aljama.

18 Ferrer Navarro, R. (2002): "Documenta Naquera", pp. 135-138.

19 Ferrer Navarro, R. (2002): “Documenta Naquera", pp. 158-159. 


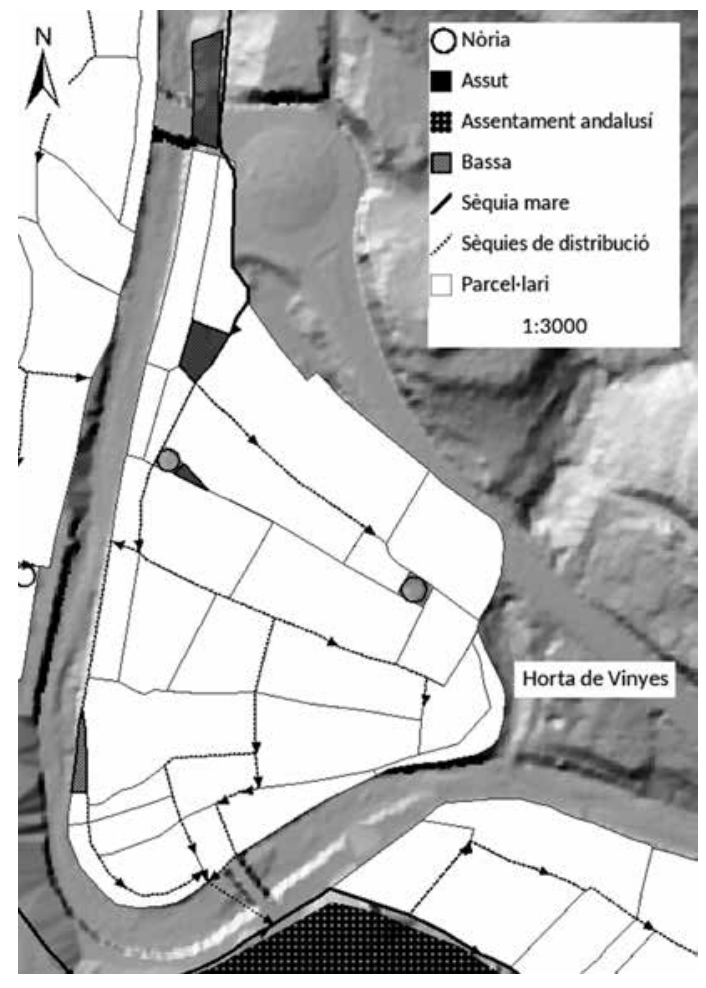

Per altre costat, a la partida de Vinyes també s'han trobat restes romanes en superfície, com fragments de tegula i dolia, sovint associades a la presència de villae romanes, així com ceràmica. ${ }^{20} \mathrm{~S}$ 'han portat a terme també alguns sondejos arqueològics, infructuosos, que no han localitzat la possible villa. Ara però, la presència d'aquestes restes indicatives d'hàbitat romà és força interessant, doncs donada la identificació prou exacta del sistema hidràulic i del parcel.lari com a medievals, i posteriors a les primeres fases andalusines de constitució de l'espai irrigat, podem veure una clara mostra de cóm les infraestructures productives medievals estan obliterant qualsevol possible element del passat romà, inconnex amb aquesta realitat.

20 Montesinos I Martínez, J. (2002): "La construcción de un paisaje. Prehistoria y Antigüedad en el término de Náquera". Las Edades de Náquera. Reconstruir la memoria. Ayuntamiento de Náquera, pp. 40-80. 


\section{L'horta del Carme, l'Horta Nova i Faixa}

Com anteriorment hem indicat, l'horta del Carme i l'horta Nova es troben separades del primer sistema hidràulic originat a l'Assut dels Moros, rebent l'aigua d'altra font situada baix del poble, i dels sobrants del primer sistema. L'aigua era retinguda, elevada i conduïda a la sèquia mitjançant un assut que hui en dia ja no existeix (però que sí que es pot situar sobre cartografia al seu lloc originari), ni són visibles restes, donades les obres modernes de canalització del barranc. El conjunt que formen aquests espais irrigats té força interès per a la recerca i l'explicació de l'evolució dels paisatges irrigats, doncs ens mostra de forma prou clara un espai de conreu irrigat originari i un espai ampliat posterior, evident també en la mateixa toponímia.

\subsection{L'horta del Carme}

Aquest espai aterrassat d'horta es troba situat al sud-est de l'actual nucli urbà, just a l'altra banda del barranc (en front de l'horta hui desapareguda de l'Alquible). Com s'ha dit, l'aigua arriba des de la font que hi ha baix del poble, anomenada actualment de Sant Francesc, i dels sobrants de les hortes del sistema situat aigües amunt, originat a l'Assut dels Moros. Un assut feia les funcions necessàries de parada i elevació de l'aigua, que era transportada a l'horta mitjançant una sèquia que traça una paràbola a la corba del barranc situada a la vora esquerra del mateix. L'espai irrigat adopta una forma que podríem anomenar de mitja lluna, semicircular quasi, si no de gota forçant un poc la percepció. Una vegada arriba l'aigua a l'horta, passada per cota més elevada (la línia de rigidesa del sistema hidràulic) una primera zona parcel.lària aterrassada que queda més baixa, arriba a una bassa de maçoneria i morter que acumula l'aigua per al reg. Des d'aquesta bassa, l'aigua es distribueix mitjançant un conjunt de sèquies esteses per l'espai de conreu segons un esquema pintiforme, permetent el reg de les parcel.les per gravetat.

L'horta del Carme apareix esmentada com espai de conreu irrigat en documentació de principis del segle XVII, en concret, en la Carta Pobla de 1609, feta just després de l'expulsió dels moriscos:

12.- Item: qu'es pague al Senyor per dret de l'aigua per a regar, per quatre arrobes d'aigua, qu'es un día, en l'horta de la Reana i en les hortes de Vinyes, del Alberch, del Alquible, i del Carm, tretce sóus cada any, i en l'Horta Nova i Faixa, a rahó de sis sóus i mig lo any per quatre arrobes, i pugen regar totes les vegades qu'es cabrá en l'any i si tendrá algún poblador mes arrobas d'aigua haja de pagar a dita rahó i prorrata. ${ }^{21}$ (sic)

21 Carta Pobla de Nàquera, 1609, Arxiu del Marqués de Boïl, en LLuCH, E. (2002): El señorío y la baronía de Náquera, 2002, p. 376. 
En aquest document podem veure cóm l'horta del Carme apareix formant una unitat fiscal amb les de Vinyes, Alberch i Alquible, diferent a la de I'horta Nova i Faixa, a banda de la de Reana, que s'esmenta la primera. Per aquest motiu, podríem hipotetitzar una cronologia propera en la construcció dels espais irrigats que apareixen com a unitat fiscal, o al menys relativament propera, i una posterior per als de l'horta Nova i Faixa, i potser també per a la Reana. En aquest sentit, malgrat prendre l'Horta Nova i Faixa l'aigua del mateix origen que l'horta del Carme, possiblement serien significativament posteriors a aquesta.

La superfície que ocupa l'horta del Carme és de 2'4 hectàrees, extensió de conreu que es situa dins de les magnituds habituals en aquests casos. Pel que fa al parcel.lari, ací trobem una mesura mitjana fornida per les estadístiques del SIG de $1083 \mathrm{~m}^{2}$, que es troba dins del ventall de mesures conegudes per a les tafulles andalusines. Dins d'aquesta horta trobem algunes parcel.les que mesuren $949 \mathrm{~m}^{2}, 1027 \mathrm{~m}^{2}, 1097 \mathrm{~m}^{2}, 1172 \mathrm{~m}^{2}$ i mesures semblants, properes al que podria ser una tafulla, però tampoc atenent a un cànon exacte. El que sí pareix ser és que ens trobem davant d'un espai on el comú de les mesures no atén necessàriament a criteris forals. Això, junt a la unitat fiscal mostrada abans amb les altres hortes analitzades prèviament, podria situar a l'horta del Carme perfectament com una ampliació de l'espai irrigat produïda segons criteris molt similars als de la construcció de les hortes de Vinyes o Reana: si no del període andalusí, sí amb una vinculació en la concepció i disseny a la pròpia societat rural andalusina. Caldria afegir ací que el topònim, Carme, faria referència a llocs de conreu de vinya, en el món andalusí, com és conegut també a Granada.

Per altre costat, a la vora de l'espai irrigat es poden trobar disperses algunes restes ceràmiques medievals, datables entre el segle XIII i el XV, però massa escasses i sense un patró suficient com per a establir localitzacions i cronologies precises de possibles jaciments. De la mateixa manera, l'espai contigu a l'horta del Carme ha patit un fort procés urbanitzador, i les poques parcel.les de secà situades sobre la sèquia mare es troben tancades com a propietat privada, per la qual cosa és quasi impossible pel moment el localitzar algun possible poblament associat a l'espai irrigat.

\subsection{L'Horta Nova i Faixa}

Baixant pel barranc, després de la corba que aquest traça després de I'horta del Carme, trobem l'Horta Nova i l'horta de Faixa, dos espais irrigats contigus que prenen l'aigua que baixa per la mateixa sèquia que abasteix l'horta del Carme, i que s'emmagatzemava en una bassa al principi del sistema, hui coberta. Els dos espais són compactes i coherents en la seua composició i en la distribució interna de l'aigua, que funciona independent- 


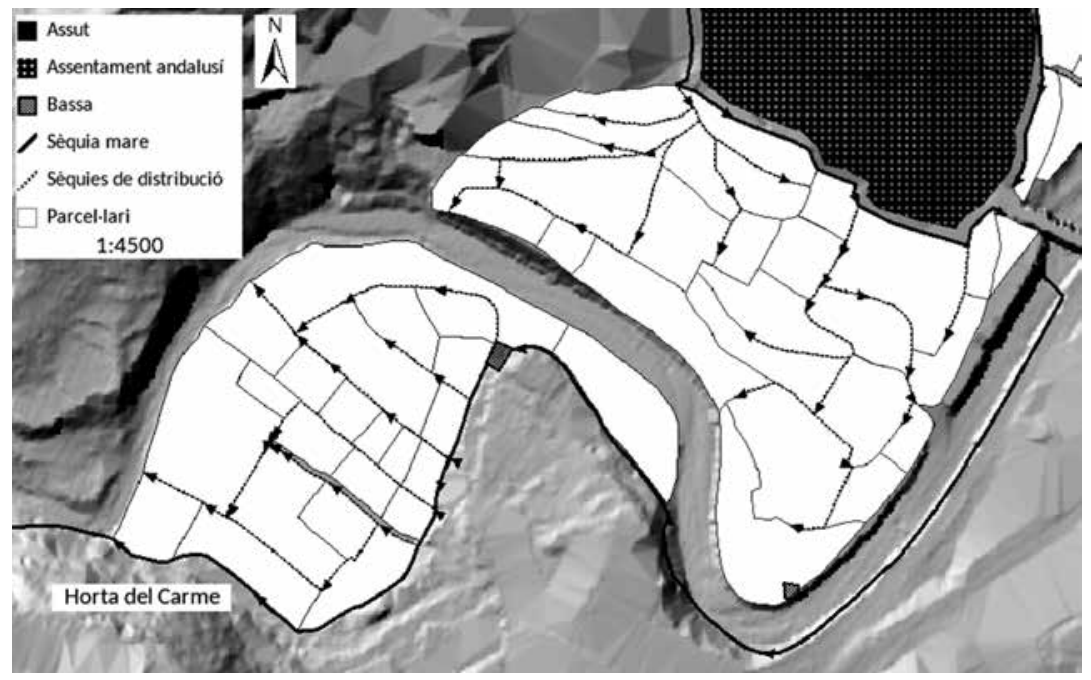

ment en un i en l'altre. En primer lloc trobem l'Horta Nova, el parcel.lari de la qual genera una forma de ventall a la vora del barranc. L'Horta Nova pareix estar ja en funcionament a començaments del segle XV, com es pot veure en les noves capitulacions signades en 1416 entre l'alqueria i el Joana Catllar, senyora de Nàquera:

Item, dels damunt dites coses ultra los dits drets paguen e sien tenguts pagar dret de alcaydia, ço es, en la orta de la alqueria dos alumts per cafís dels dits blats e altres espelts a senyor e en la orta nova no sien tenguts pagar a senyor sino hun almut per cafiç per raho del dit dret de alcaydia, e en lo sequa e en la vinya vella no paguen alguna cosa per lo dit dret de alcaydia.

(...)

Item, per la orta nova paguen de peyta en lo mes de febrer cascun any LXXXIIII sous. ${ }^{22}$

Ací les parcel.les mostren una prou forta regularitat $\mathrm{i}$ tendència a la ortogonalitat, i el reg, difús, des de la sèquia mare irrigant parcel.les a un costat i altre dels braços de distribució que baixen vers el barranc. L'estructura de les sèquies s'adapta a la parcel.lació ortogonal, i no al revés ni al microrelleu. Això és signe d'un criteri a la construcció de l'espai irrigat lligat a una planificació molt concreta del repartiment de les parcel.les de terra, que no

22 Ferrer Navarro, R. (2002): "Documenta Naquera" en Las Edades de Náquera. Reconstruir la memoria. Ayuntamiento de Náquera, pp 135-138 
atendria a la gestió collectiva i comunitària de l'ús de l'aigua com a prioritat. Aquest espai irrigat ocupa una superfície de 2'7 hectàrees, dimensió coherent amb allò vist als altres espais irrigats. Ací les mesures de les parcel.les generen qüestions i preguntes força interessants per a la recerca. La mitjana parcel.lària és de $500 \mathrm{~m}^{2}$, i trobem cites en la documentació d'inicis del segle XVII a unitats forals de mesura, com la fanecada i la barcella, $i$ també apareixen almuds.

Item: en la partida de la Huerta Nueva, un pedazo de tierra huerta que será una hanegada de tierra con cinco pies de garroferas veras y una borde y un olivastre que en tiempo de los cristianos nuevos confrontaba con tierra de Ramonet y con el pie de la montaña y ahora confronta con tierra de Francisco Épila, con tierra de Joan de Fos, con tierra de Joan Viñan y con el pie de la montaña, poseélo la iglesia.

(...)

Item: cinco pedacitos de tierra huerta en la misma partida todos contiguos, juntos unos de otros, que todos serán una barchilla de sembradura, con ocho garroferas veras y otras tantas bordes y cuatro oliveras buenas y un olivastre que en tiempos de los cristianos nuevos confrontaba con el barranco a la parte de abajo. ${ }^{23}$

La fanecada té una mesura de $831^{\prime} 08 \mathrm{~m}^{2}$, mentre que la barcella seria d'una extensió de $415^{\prime} 52 \mathrm{~m}^{2}$, equivalent a quatre almuds. Trobem a l'espai de l'Horta Nova algunes parcel.les de mesures molt properes $\left(859 \mathrm{~m}^{2}\right.$, $431 \mathrm{~m}^{2}$, etc.), tenint en compte que és força complicat generar, sobre tot amb tècniques i mitjans preindustrials, parcel.les de mesures exactes en un pendent que ha de ser aterrassat. També localitzem alguna parcel.la que tindria la mesura del que es coneixia com un "hort", que seria fanecada i mitja, amb $1259 \mathrm{~m}^{2}$ sobre el terreny. Ara però, també localitzem parcel.les amb mesures situades en el ventall de valors possibles de la tafulla andalusina, com $925 \mathrm{~m}^{2}$ (tant en una parcel.la com en una unitat de reg formada per dos terrasses), $938 \mathrm{~m}^{2}, 1010 \mathrm{~m}^{2}$ ó $1085 \mathrm{~m}^{2}$. Aquest fet introdueix un element de complexitat, que caldrà valorar amb una recerca més detallada.

L'horta de Faixa, contigua a l'Horta Nova, mostra una forma allargada (com el seu nom indica), vora el barranc, i pren l'aigua de la sèquia que 
passa per l'Horta Nova. Formalment és un conjunt compacte i coherent en sí mateix, que no té relació estructural amb el ventall que forma l'horta veïna, i per això i per la seua situació podem deduir que la seua construcció és posterior a la de l'Horta Nova. El seu parcel-lari és totalment regular i ortogonal, en retícula, amb la distribució de l'aigua a través de les seves sèquies adaptat a aquesta condició. Les sèquies de distribució baixen perpendiculars vers el barranc des de la sèquia mare, delimitant blocs d'unes tres parcel.les regulars. Ací la mitjana parcel.lària està en $466 \mathrm{~m}^{2}$, mesura que no aniria lluny de la barcella. Ací només hi ha una parcel.la que aparentment podria ser pròxima a les mesures abans esmentades per als canons andalusins, amb $932 \mathrm{~m}^{2}$, que però resulta ser una fanecada i un almud, de manera prou exacta. Estaríem davant de mesures parcel.làries, i tècniques de construcció de l'espai irrigat, plenament corresponents a esquemes de la societat feudal.

En aquests dos casos ens trobem amb un molt possible exemple d'ampliació de l'espai de conreu irrigat com a iniciativa i estratègia de la senyoria feudal, i sota els seus criteris, malgrat la mà d'obra siga mudèjar. Un exemple que pot valorar-se com semblant ha sigut estudiat recentment per Ferran Esquilache en Llombai. ${ }^{24}$

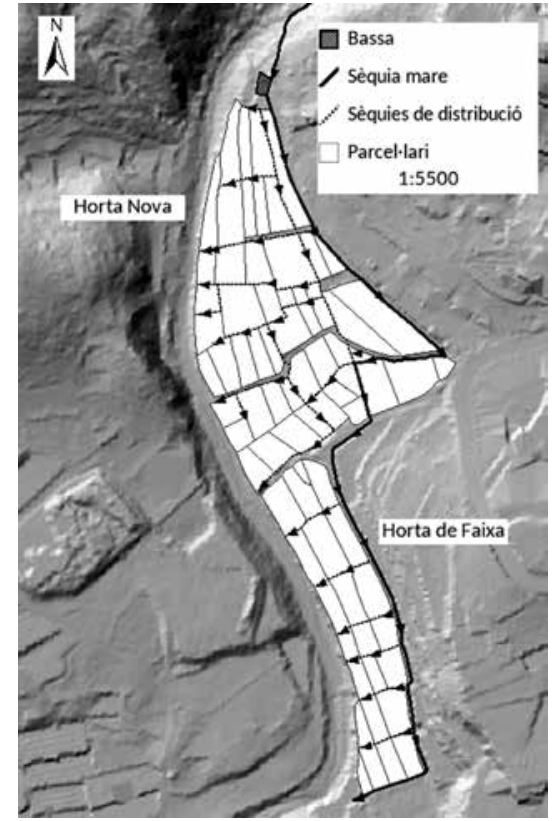

24 Esquilache Martí, F. (2009): "Sobre la rigidez de los sistemas hidráulicos y la evolución del parcelario en las huertas de moriscos. El caso de la acequia de Alèdua". Actas del XI Simposio Internacional de mudejarismo. Teruel, pp 379-392. 


\section{Proposta per a una estratigrafia dels paisatges irrigats a Nàquera}

L'estudi dels paisatges d'horta de Nàquera mitjançant les tècniques de l'arqueologia hidràulica ens permet percebre aquests com un ens complex i dinàmic, producte de la interacció dialèctica entre la societat rural de Nàquera de cada moment històric i el seu entorn i de les seves pròpies dinàmiques socio-econòmiques. Quan ens proposem una recerca en l'àmbit de l'arqueologia rural, és fonamental que sapiguem veure els jaciments des d'un punt de vista ample, plantejant-nos l'anàlisi de zones arqueològiques extenses, més enllà del clàssic "jaciment-lloc", com s'estableix a la proposta de protocol per a la recerca arqueològica agrària que fan Kirchner i altres ${ }^{25}$. En aquest cas és plenament visible aquesta realitat: l'estudi de les hortes, tant existents com desaparegudes en Nàquera, ens permet conèixer les infraestructures productives de l'antiga societat andalusina i la seua evolució durant l'Edat Mitjana. De fet, els espais aterrassats de conreu irrigat i les seves xarxes hidràuliques, en tant que elements antròpics, espais i elements construïts en el passat, són susceptibles de ser estudiats arqueològicament, i cal que siguen considerats jaciments arqueològics plenament. En aquest sentit hem de veure les hortes de Arrabal, Alquible, Rere el Forn, com infraestructures productives estratigràficament contemporànies a l'assentament andalusí de Nàquera, en la seva primera etapa, al qual estarien vinculades, com es pot veure en el vincle estructural entre el traçat de les sèquies mare que abasteixen als camps i la delimitació de l'assentament humà. Ara però, les cronologies que poden donar-se pel moment serien molt relatives, donada la mancança d'excavacions arqueològiques suficients i que puguen aportar datacions exactes. Pel moment, només podríem establir un moment indeterminat d'instal.lació del grup andalusí i de la construcció llavors simultània de l'assentament i les hortes entre possiblement el segle $\mathrm{X} i$ els inicis de la presència islàmica, al VIII. Possiblement poguera proposar-se la fi de la fitna del període emiral com a moment d'estabilització. ${ }^{26}$ Per altre costat, malgrat la gran estabilitat dels sistemes hidràulics tradicionals, i sobre tot d'origen andalusí, ${ }^{27}$ també poden veure's afectats per eventuals variacions, cosa que faria que al si dels matei-

25 KIRCHNeR, H. et al. (2010): Por una arqueología agraria. Perspectivas de investigación sobre espacios de cultivo en las sociedades medievales hispánicas. BAR International Series 2062, Oxford. pp 185-198

26 Hi ha un topònim antic: el tossal de l'ermita s'anomenava La Ràpita, cosa que podria associar-se amb presència militar d'eixe període de fitna. Ara però, respecte a això, cal desenvolupar més la recerca, resultant aquest raonament pel moment especulatiu.

27 Com explica molt raonadament Miquel Barceló, doncs donat el sistema de conducció i distribució de l'aigua a través de la gravetat, qualsevol modificació al sistema hidràulic podria comprometre el correcte moviment de l'aigua a aquest. 
xos espais irrigats fora possible diferenciar zones de cronologia diversa, com es podria intuir de la presència d'algunes restes molt concretes de parcel.les amb mesures clarament andalusines, junt a zones de mesures parcel.làries o morfologies diferents, que es podrien deure a refaccions de parcel.les en zones que es poden haver veure afectades per fenòmens de forta escorrentia estacional. Així, afinant molt més la recerca, podríem establir també estratigrafies internes als espais irrigats que servisquen per a explicar i entendre els diferents esdeveniments en la llarga durada en els mateixos. Pel que fa a la resta, l'anàlisi de la xarxa hidràulica de sèquies, diferenciant les seues jerarquies tant pel que fa a la relació estructural com als drets a l'ús de l'aigua podem establir també l'anterioritat o posterioritat de construcció dels diversos espais irrigats, per la qual cosa la identificació tant de les diferents sèquies (sèquia mare, braços de distribució, regadores) com de les seves interrelacions, amb la prospecció sobre el terreny segons metodologia de l'arqueologia hidràulica i junt a l'anàlisi de les diferents morfologies o tipologies i a les estructures parcel.làries vinculades, es pot bastir també tota la relació estratigràfica entre aquestes i per tant els seus espais de conreu irrigat. Així, es podria a grans trets identificar tota una fase d'ampliació dels espais d'horta, formada per les hortes de la Reana, Vinyes i el Carme, que respondrien a dinàmiques de creixement siga en el període andalusí o en el feudal, on el pes de la societat local andalusina en quant a planificació i decisions seria major, i una darrera, que correspondria a l'Horta Nova i Faixa, constrü̈des sota criteris i direcció de la senyoria feudal.

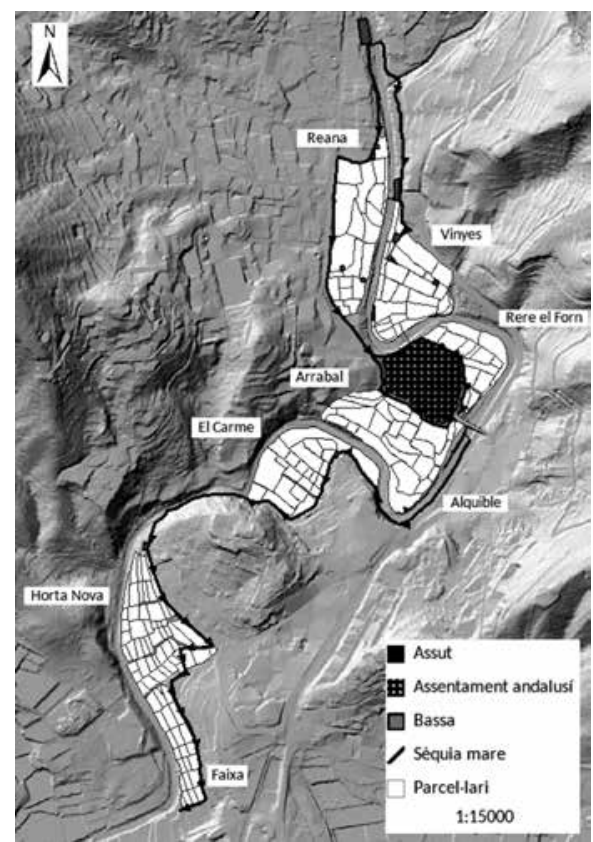




\section{Biblografia}

BarCeló, M. (1989): "El diseño de espacios irrigados en Al-Andalus: un enunciado de principios generales". I Coloquio de Historia y Medio Físico, Instituto de Estudios Almerienses. Departamento de Historia.

Domingo Pérez, C. (1981-21): "Nota sobre medidas agrarias valencianas". Estudis: Revista de Historia Moderna, Publicacions de la Universitat de València, pp. 7-14.

ESQUILACHE MARTí, F. (2009): "Sobre la rigidez de los sistemas hidráulicos y la evolución del parcelario en las huertas de moriscos. El caso de la acequia de Alèdua". Actas del XI Simposio Internacional de mudejarismo. Tervel, pp. 379-392.

Gil I Ortega, F.; Navarro I Tomàs, A. (1997): Toponímia rural de Nàquera. Tòpica Edetana, Institut d'Estudis Comarcals del Camp del Túria. Buñol. Guck, T. (2007): Paisajes de conquista. Cambio cultural y geográfico en la España medieval. Publicacions de la Universitat de València.

GuINOT, E.; Selma, S. (2008): "L'estudi del paisatge històric de les hortes mediterrànies: una proposta metodològica". Revista Valenciana d'Etnologia, 3, pp 101-124. València.

KIRCHNER, C. (1995): "Construir el agua. Irrigación y trabajo campesino en la Edad Media". Arbor, CLI. 593, pp. 35-64.

KIRCHNER, H. et al. (2010): Por una arqueología agraria. Perspectivas de investigación sobre espacios de cultivo en las sociedades medievales hispánicas. BAR International Series 2062. Oxford.

LLUCH, E. (2002): El señorío y la baronía de Náquera, Ajuntament de Nàquera.

Retamero, F. (2006): "Lo que el tamaño importa. Cuándo y por qué se modificaron los antiguos sistemas hidráulicos andalusíes". Arqueología Espacial, 26. pp 293-310.

Ruiz Pérez, J.M.; Montesinos I Martínez, J.; Ferrer Navarro, R.; Pingarón-Esaín SECO, F. (2002): Las Edades de Náquera. Reconstruir la memoria. Ayuntamiento de Náquera.

TORRó, J. (2005): "Terrasses irrigades a les muntanyes valencianes. Les transformacions de la colonització cristiana." Afers, 51, pp. 301-356. 